ARTICLE

\title{
Light-driven decarboxylative deuteration enabled by a divergently engineered photodecarboxylase
}

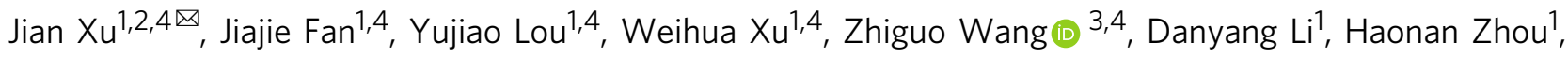
Xianfu $\operatorname{Lin}^{1} \&$ Qi Wu (i) ${ }^{1 凶}$

Despite the well-established chemical processes for C-D bond formation, the toolbox of enzymatic methodologies for deuterium incorporation has remained underdeveloped. Here we describe a photodecarboxylase from Chlorella variabilis NC64A (CVFAP)-catalyzed approach for the decarboxylative deuteration of various carboxylic acids by employing $\mathrm{D}_{2} \mathrm{O}$ as a cheap and readily available deuterium source. Divergent protein engineering of WTCVFAP is implemented using Focused Rational Iterative Site-specific Mutagenesis (FRISM) as a strategy for expanding the substrate scope. Using specific mutants, several series of substrates including different chain length acids, racemic substrates as well as bulky cyclic acids are successfully converted into the deuterated products ( $>40$ examples). In many cases WT-CVFAP fails completely. This approach also enables the enantiocomplementary kinetic resolution of racemic acids to afford chiral deuterated products, which can hardly be accomplished by existing methods. MD simulations explain the results of improved catalytic activity and stereoselectivity of WT CVFAP and mutants.

\footnotetext{
${ }^{1}$ Center of Chemistry for Frontier Technologies, Department of Chemistry, Zhejiang University, Hangzhou, P. R. China. ${ }^{2}$ College of Biotechnology and Bioengineering, Zhejiang University of Technology, Hangzhou, P. R. China. ${ }^{3}$ Institute of Aging Research, School of Medicine, Hangzhou Normal University, Hangzhou, P. R. China. ${ }^{4}$ These authors contributed equally: Jian Xu, Jiajie Fan, Yujiao Lou, Weihua Xu, Zhiguo Wang. ${ }^{\varpi_{e}}$ ail: jianxu@zjut.edu.cn; wuqi1000@163.com
} 
$\mathrm{D}$ euterium labeling is an attractive and powerful tool in the investigation of metabonomics, proteomics, mass spectrometry studies and reaction mechanisms ${ }^{1-3}$. In pharmaceutical chemistry, the introduction of C-D bonds has recently aroused scientific interests as an effective approach to modify the absorption, distribution, and toxicological properties of therapeutic drug molecules, which is due to the higher chemical inertness of $\mathrm{C}-\mathrm{D}$ bonds compared with the $\mathrm{C}-\mathrm{H}$ bonds ${ }^{4}$. Moreover, Austedo $^{\mathrm{TM}}$, the first deuterated drug approved in 2017 by the US Food and Drug Administration, has been a major driving force for the booming development of the research of deuterium incorporation ${ }^{5}$.

A number of elegant chemical methods for deuteration have been exploited over the past decades ${ }^{6-11}$. However, most of these approaches rely on transition metal complexes or harsh reaction conditions, which may suffer from high costs and raise environmental issues. For example, highly active Hydrogen Isotope Exchange (HIE) reactions by heterogeneous approaches has been found with palladium, platinum, rhodium, nickel, and ruthenium catalysts $^{11}$. Moreover, among all transition metals employed in homogeneous HIE reactions, iridium is arguably the most widely studied ${ }^{8,9,11}$. Recently, photocatalytic deuteration of synthetically valuable organic molecules through mild routes has received considerable attentions ${ }^{12,13}$. MacMillan's group developed a strategy for direct deuteration of pharmaceutical compounds with a photoredox-hydrogen atom transfer-catalyzed process in equilibrium with $\mathrm{D}_{2} \mathrm{O}^{14}$. Typically, heterogeneous metal-catalyzed HIE as well as some photocatalytic deuterations results in relatively unspecific incorporation of numerous deuterium atoms into a molecular substrate ${ }^{11,13}$. Accordingly, there is a great need for the development of mild and selective methodologies for the incorporation of a single deuterium. Deuterodefunctionalization has recently found widespread application in the selective incorporation of deuterium ${ }^{15}$, and a few kinds of deuterodefunctionalization transformations have been developed, such as deborylative ${ }^{14}$, decarboxylative ${ }^{16-18}$, deoxygenative ${ }^{19}$, and dehalogenative ${ }^{20-22}$ deuteration. Among them, protodecarboxylation reaction is of high preparative utility in this field, first as a constructive model method for selective deuteration and also as a precursor step of decarboxylative cross-coupling reaction for regiospecific $\mathrm{C}-\mathrm{C}$ and $\mathrm{C}-$ heteroatom bond formation ${ }^{23,24}$. In these processes, precious metals such as palladium, silver, were principally used as catalysts, although some coppercatalyzed deuterodecarboxylations ${ }^{16}$ were also reported as exceptional cases, while they usually hampered by the extremely high temperature and costly ligands ${ }^{23}$. Recently, some mild deuterium exchange reaction of free carboxylic acids by photochemical decarboxylation have also been successfully demonstrated ${ }^{25,26}$.

Biocatalysis has emerged as a powerful tool in organic synthetic chemistry because enzymes generally display high activity and selectivity under mild reaction conditions ${ }^{27-30}$. Although the chemical deuteration methods have been well studied, the toolbox of enzymatic methodologies for deuterium incorporation has remained underdeveloped ${ }^{31,32}$. To the best of our knowledge, there are mainly two kinds of enzymatic deuteration methodologies reported so far. Biocatalytic reductive deuteration ${ }^{31,33-38}$ requires a supply of deuterated, reduced cofactor, [4-D]-NADH, which must be continually regenerated in situ by the appropriate dehydrogenase enzyme, in conjunction with a superstoichiometric supply of a sacrificial deuterated reductant, Dethanol, D-isopropanol, D-glucose or D-formate ${ }^{33,34}$. More recently, several works successfully demonstrated $\mathrm{H}_{2}$-driven [4$\mathrm{D}]-\mathrm{NADH}$ recycling using hydrogenase and NAD+ reductase, with $\mathrm{D}_{2} \mathrm{O}$ supplying the deuterium atoms ${ }^{31,36,37}$. Various NADHdependent reductases such as ADH (Alcohol dehydrogenase) ${ }^{31,36}$ and IRED (Imine reductase) ${ }^{37}$ can provide corresponding deuterated chiral alcohols and amines. Another kind of enzymatic deuteration methodology was deuterodecarboxylations catalyzed by aromatic L-amino acid decarboxylase, mainly reported by Kańska group ${ }^{39-41}$. This method can prepare specific deuterated aromatic amines starting from various aromatic L-amino acids such as L-tryptophan, L-phenylalanine, L-tyrosine, and their derivatives by applying the appropriate aromatic L-amino acid decarboxylase in deuteriated media. Accordingly, the substrate scope of these deuterodecarboxylations catalyzed by aromatic Lamino acid decarboxylase is very narrow. Indeed, biocatalytic aliphatic decarboxylative deuterations providing deuterated alkanes have never been reported.

Recently, photoenzymes, which directly utilize visible light to activate catalytic activity, have been exploited to generate new carbon skeletons, resulting in the diversification of natural products with improved bioactivities ${ }^{42}$. For example, Hyster's group has utilized photoexcited natural enzymes to be competent for new transformations, including reduction, dehalogenation, deacetoxylation or even cyclization ${ }^{43-48}$. Fatty acid photodecarboxylase from Chlorella variabilis NC64A (CvFAP) is another type of photoenzymes discovered by Beisson and coworkers ${ }^{49}$. In other key studies, Hollmann's group has brought $C \nu \mathrm{FAP}$ into chemistry by designing cascade reactions or decoy molecule ${ }^{50-52}$. Scrutton's group has developed a strategy for the production of bio-alkane gas with engineered CvFAP ${ }^{53}$. In conjunction with our efforts, the feasibility of kinetic resolution of $\alpha$ functionalized carboxylic acids by engineered $C \nu \mathrm{FAP}$ has been investigated ${ }^{54}$. In the proposed mechanism of $C \nu \mathrm{FAP}$-catalyzed decarboxylation, alkyl carboxylate is activated by single electron transfer (SET) with FAD* to give a carboxyl radical, which undergoes facile decarboxylation to yield the corresponding alkyl radical ${ }^{55,56}$. On this basis, we questioned whether we could exploit the alky radical to access deuterated products. We speculated that if $\mathrm{D}_{2} \mathrm{O}$ is present, the generation of active deuterium would subsequently interact with the alkyl radical, resulting in the formation of a $\mathrm{C}-\mathrm{D}$ bond through hydrogen atom transfer (HAT) (Fig. 1a).

Herein, we report an enzymatic methodology that introduces deuterium into organic molecules with $\mathrm{D}_{2} \mathrm{O}$ as an easily handled, cheap, and readily available deuterium source under mild reaction conditions. Although the biocatalysts can hardly be "universal," we engineered $C \nu \mathrm{FAP}$ by divergent pathways for a broad range of substrates. Using specific mutants, several series of substrates including different chain length acids, racemic substrates as well as bulky cyclic acids were successfully converted into the deuterated products.

\section{Results and discussion}

Reaction conditions. We commenced our study by evaluating the viability for the decarboxylation deuterium incorporation with palmitic acid (1A , Table 1) as starting material because it is naturally occurring and has the highest decarboxylation activity under the catalysis of WT- $C \nu \mathrm{FAP}^{49,50}$. After irradiation for $12 \mathrm{~h}$ with $\mathrm{D}_{2} \mathrm{O}$ as solvent, the reaction proceeded smoothly to give the desired product in $99 \%$ yield with $93 \%$ D-incorporation (Table 1, entry 1), demonstrating the feasibility of the hypothesis. Importantly, the use of free FAD cofactor gave no observable product, implying the necessity of the protein scaffold (Table 1, entry 2). As expected the use of DMSO or $\mathrm{CH}_{3} \mathrm{CN}$ as co-solvent to improve the substrate solubility resulted in a significant increase in efficiency (Table 1, entry 5, 6). Further control experiments revealed the requirement of $C v \mathrm{FAP}$ and a light source (Table 1 , entry 3,4$)$. Moreover, in contrast to traditional chemical photoredox deuteration, we discovered that this bio-radical 
a

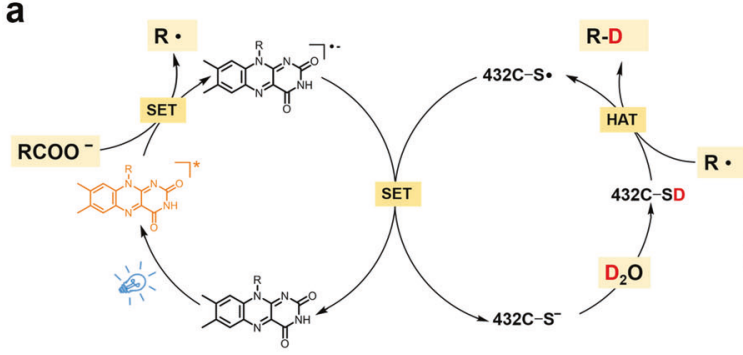

b

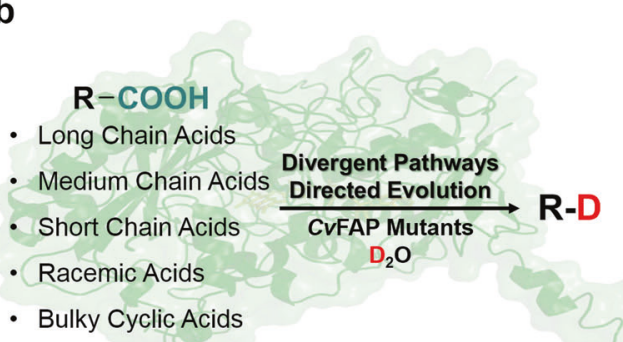

c

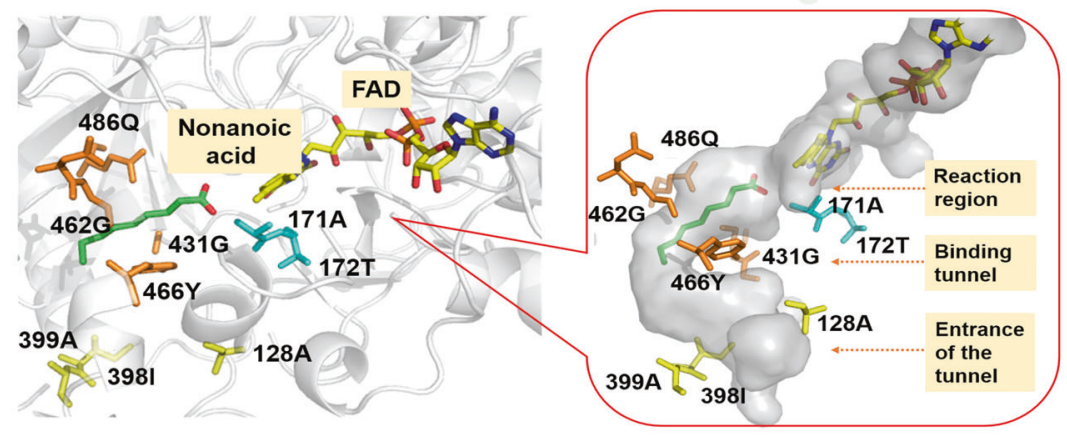

d

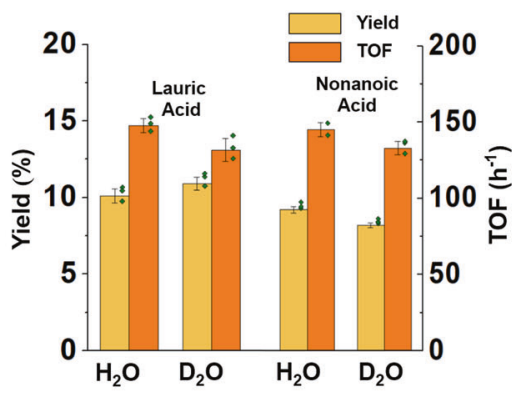

e

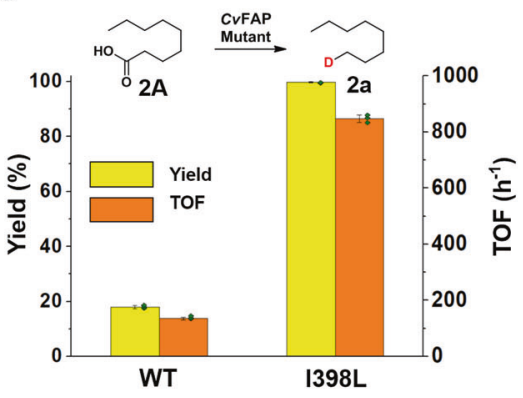

$\mathbf{f}$

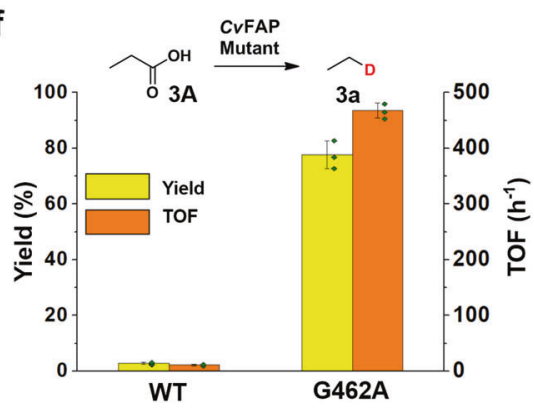

g

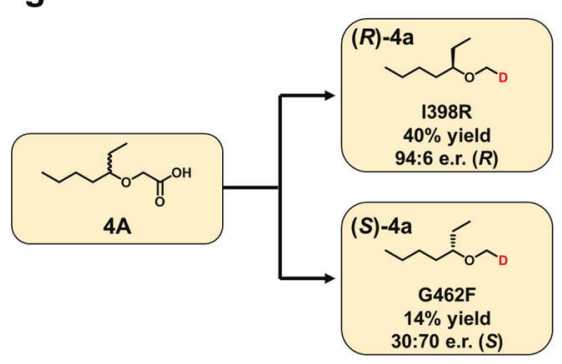

h

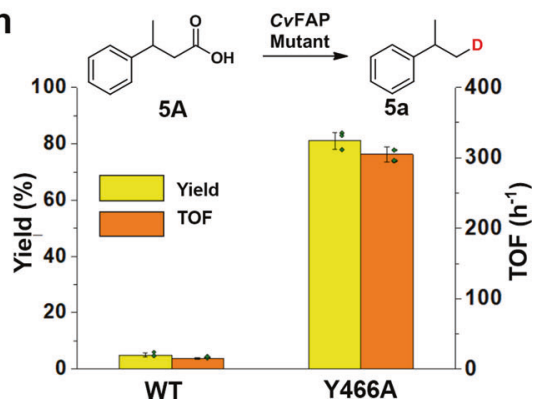

Fig. 1 Design of CvFAP-catalyzed decarboxylative deuteration and divergent directed evolution of CvFAP. a Proposed mechanism of CvFAP-catalyzed decarboxylative deuteration. b Design of divergent directed evolution of CVFAP toward various substrates. c Docking result with nonanoic acid (green) and selected hot positions for protein engineering (PDB:5NCC) ${ }^{49}, F A D$ (flavin adenine dinucleotide) and some representative residues located at the entrance of the substrate pocket (yellow), binding region (orange) and reaction region (cyan) are represented by sticks with different colors. $\mathbf{d}$ The influence of kinetic isotope effect on the reaction activity. e The comparison of yields and TOF between WT-CVFAP and the best mutant (I398L) for the medium chain acid. $\mathbf{f}$ The comparison of yields and TOF between WT-CVFAP and the best mutant (G462A) for the short chain acid. $\mathbf{g}$ The enantiodivergent decarboxylative deuteration catalyzed by I398R and G462F mutants, respectively. $\mathbf{h}$ The comparison of yields and TOF between WT-CVFAP and the best mutant (Y466A) for bulky cyclic acid. Error bars represent the mean \pm SD of three independent experiments. Source data are provided as a Source Data file.

transformation can be run in a manner open to air and without the requirement of extra thiol as a hydrogen atom transfer (HAT) additive (Table 1 , entry 8$)^{13}$ Lastly, the influence of the various cosolvent addition, substrate concentration and reaction time were further studied and the best result of WT C $v$ FAP-catalyzed decarboxylation deuterium of palmitic acid was obtained from the reaction with $100 \mathrm{mM}$ substrate concentration and $20 \%$ vol. DMSO as cosolvent after $12 \mathrm{~h}$ (Supplementary Figs. 1-3).
Moreover, the influencing factor for D-incorporation was also investigated. According to the reaction mechanism, we considered the major influencing factor for high D-incorporation is the concentration of residual $\mathrm{H}_{2} \mathrm{O}$ in the reaction system (Supplementary Fig. 4). The extent of labeling roughly follows the ratio of $\mathrm{D}_{2} \mathrm{O}$ in the solvent mixture, suggesting kinetic isotope effect is small. With the prolongation of freeze-drying time of enzymes and the continuous removal of $\mathrm{H}_{2} \mathrm{O}$, the D-incorporation 
Table 1 Reaction optimization and control experimentsa.

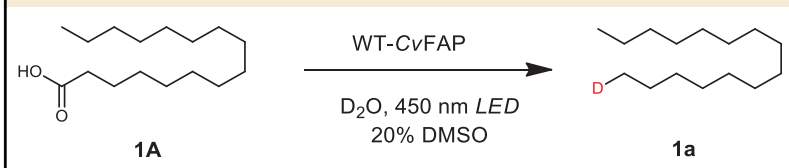

\begin{tabular}{|c|c|c|c|}
\hline Entry & Deviation from standard conditions & Yield $(\%)^{\mathbf{b}}$ & D-incorporation $(\%)^{d}$ \\
\hline 1 & Standard conditions & $99\left(75^{c}\right)$ & 93 \\
\hline 2 & Free FAD & 0 & - \\
\hline 3 & No CVFAP & 0 & - \\
\hline 4 & No light & 0 & - \\
\hline 5 & No DMSO & 17 & 93 \\
\hline 6 & $\mathrm{CH}_{3} \mathrm{CN}$ instead of DMSO & 96 & 95 \\
\hline 7 & $\mathrm{H}_{2} \mathrm{O}$ instead of $\mathrm{D}_{2} \mathrm{O}$ & 99 & 0 \\
\hline 8 & Air & 99 & 93 \\
\hline
\end{tabular}

improved significantly. Thus, we chose $10 \mathrm{~h}$ for the freeze-drying treatment of $C v \mathrm{FAP}$ before starting reactions, it is sufficient to ensure high D-incorporation.

Scope of WT-C $v$ FAP catalyzed decarboxylative deuteration. With the optimized conditions in hand, we surveyed the substrate scope of this bio-deuteration process. As depicted in Fig. 2, a wide range of differently substituted long chain fatty acids were readily converted into their corresponding deuterated compounds with high yields and excellent D-incorporation (Fig. 2, 1a-1k) It is worth noting that introducing active groups such as $-\mathrm{OH},-\mathrm{O}-$, or -alkenyl moieties on the carbon chain did not affect the reaction results adversely. Natural products such as oleic and linoleic acids were also suitable substrates, affording the corresponding products with good yields and excellent Dincorporations (1d, 1e). Unfortunately, when switching the long chain acids to short, medium chain acids or aromatic acids, the products yields decreased significantly (Fig. 2, 2a, 5a). To overcome this limitation, we employed divergent directed evolution for $C v \mathrm{FAP}$ to access different functionalized variants for accepting a diversity of substrates.

Divergent directed evolution of $C \boldsymbol{v F A P}$ for diverse substrates. We focused our initial directed evolution route on the deuteration reaction of medium chain fatty acids. Following a thorough analysis of the crystal structure of the C $v \mathrm{FAP}$ active site ${ }^{49}$ into which we docked nonanoic acid as the model substrate (Fig. 1c), we divided the active site into three domains, the entrance of the substrate pocket, the hydrophobic binding region and the reaction region. The hot sites for mutation lining the binding and reaction region (CAST sites) ${ }^{29,57}$ were selected to be the largest potential contributors in influencing the activity. Meanwhile, other sites at the entrance of the binding pocket which were relatively far from the substrate were also selected for mutagenesis due to the consideration of possible cooperative mutational effects. Since the kinetic isotope effect shows a small effect on the activity of $C v$ FAP -catalyzed decarboxylation (Fig. 1d), and considering economical factors and operation convenience, we chose $\mathrm{H}_{2} \mathrm{O}$ as solvent in the model reactions for subsequent screening of mutant libraries. We then proceeded with protein engineering under the guidance of "Focused Rational Iterative Site-specific Mutagenesis" (FRISM) ${ }^{58,59}$, which constitutes an effective fusion of directed evolution and rational design. FRISM is an offspring of CAST/ISM ${ }^{29,57}$, but it does not require the formation of mutant libraries generated by focused saturation
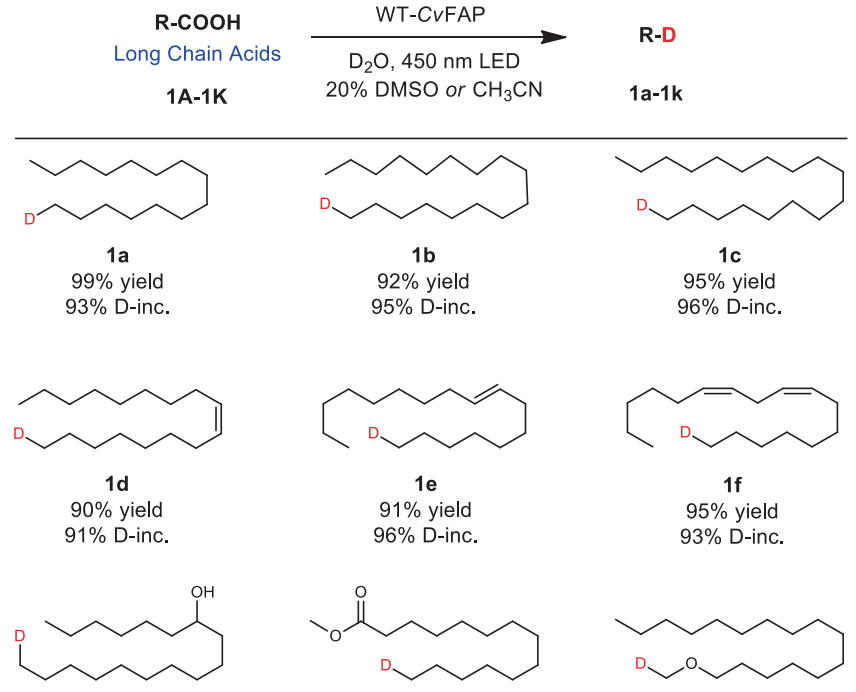

$1 \mathrm{~g}$

$95 \%$ yield

$87 \%$ D-inc.

$1 \mathrm{~h}$

$95 \%$ yield
$96 \%$ D-inc.

$1 \mathrm{i}$

$95 \%$ yield
$96 \%$ D-inc.
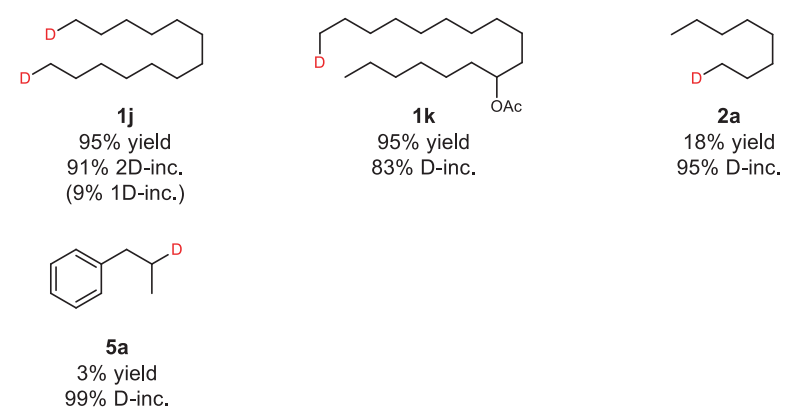

$2 \mathrm{a}$

$18 \%$ yield
$95 \%$ D-inc.

Fig. 2 Deuteration scope: long chain acids. Reaction conditions: Substrate ( $0.40 \mathrm{mmol}$ ), crude enzyme powder (containing CvFAP about $20 \mathrm{mg}), \mathrm{D}_{2} \mathrm{O}$ (4 mL), DMSO or $\mathrm{CH}_{3} \mathrm{CN}(1 \mathrm{~mL}), 450 \mathrm{~nm}$ LED (light-emitting diode),

$20^{\circ} \mathrm{C}, 12 \mathrm{~h}$. Yields were determined by GC. D-inc. data were determined by ${ }^{1} \mathrm{H}$ NMR or HRMS.

mutagenesis, and therefore circumvents laborious screening 54,60 . Accordingly, site-specific mutagenesis with the introduction of differently sized amino acids, including alanine (A), leucine (L), and phenylalanine $(\mathrm{F})$, was first used to modify the volume of 


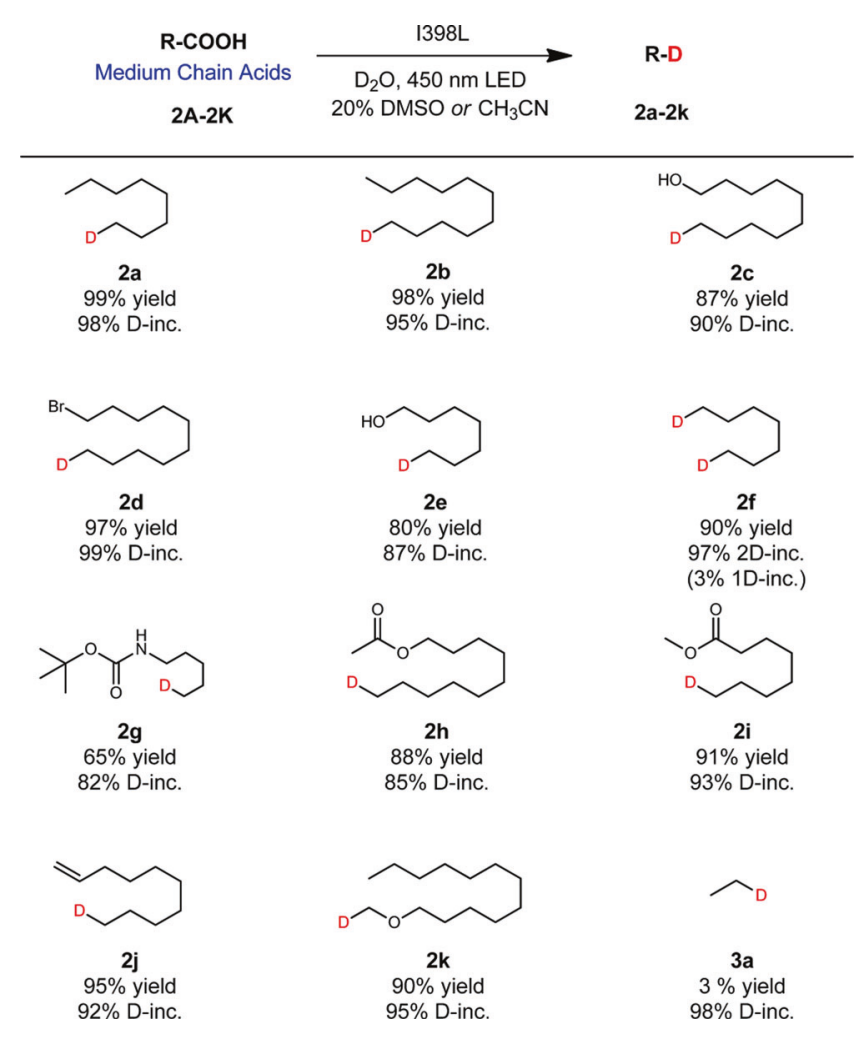

Fig. 3 Deuteration scope: medium chain acids. Reaction conditions: Substrate $(0.40 \mathrm{mmol})$, crude enzyme powder (containing CVFAP about $20 \mathrm{mg}), \mathrm{D}_{2} \mathrm{O}(8 \mathrm{~mL}), \mathrm{DMSO}$ or $\mathrm{CH}_{3} \mathrm{CN}(2 \mathrm{~mL}), 450 \mathrm{~nm} \mathrm{LED}, 20^{\circ} \mathrm{C}, 12 \mathrm{~h}$. Yields were determined by GC. D-inc. data were determined by ${ }^{1} \mathrm{H}$ NMR or HRMS.

these hot-spots. Afterwards, the best hits were then tested with similarly sized amino acids $\left(\mathrm{A}^{+}, \mathrm{L}^{+}\right.$, or $\left.\mathrm{F}^{+}\right)$as an "extensionlibrary" for possible activity improvement. $\mathrm{A}^{+}, \mathrm{L}^{+}$, and $\mathrm{F}^{+}$ include $\mathrm{G}, \mathrm{V} / \mathrm{C} / \mathrm{I} / \mathrm{M}$ and $\mathrm{Y} / \mathrm{W}$, respectively. To our surprise, most tested mutations at the binding or reaction region displayed only slight or no influence on the reaction activity of nonanoic acid (Supplementary Fig. 5), while one beneficial mutation, I398L which is located at the entrance to the binding pocket, showed a nearly 10 -fold improvement of activity, thereby furnishing a satisfactory yield and catalytic efficiency (Fig. 1e). Another positive mutation, A128L, is also at the entrance, and likewise showed a significant enhancement of activity (Yield 93\%, TOF $725 \mathrm{~h}^{-1}$ ).

Next, we investigated the scope of substrates using variant I398L, which is by far the best mutant (Fig. 3). To our satisfaction, the decarboxylative deuteration reactions of these tested medium chain acids derivatives were successfully realized under the catalysis of I398L in good yields and D-incorporation. Thus, promising functional group tolerance was accomplished by generating and screening less than 30 variants (Supplementary Fig. 5). Nonetheless, the catalytic activity of the I398L mutant decreased significantly when the carbon chain becomes shorter (Fig. 3, 3a), which prompted us to search a new mutant to accept short chain acids.

With these considerations in mind, propionic acid was used as the model substrate for the further divergent screening of FRISM mini-libraries. To our delight, mutant G462A furnished a notable improvement of yields $(78 \%)$ and TOF $\left(468 \mathrm{~h}^{-1}\right)$ (Fig. 1f). A number of short chain acids were then subjected to the best mutant, and indeed the corresponding deuterated products $\mathbf{3 a}-\mathbf{3 g}$ were obtained in high yields (Fig. 4). Particularly

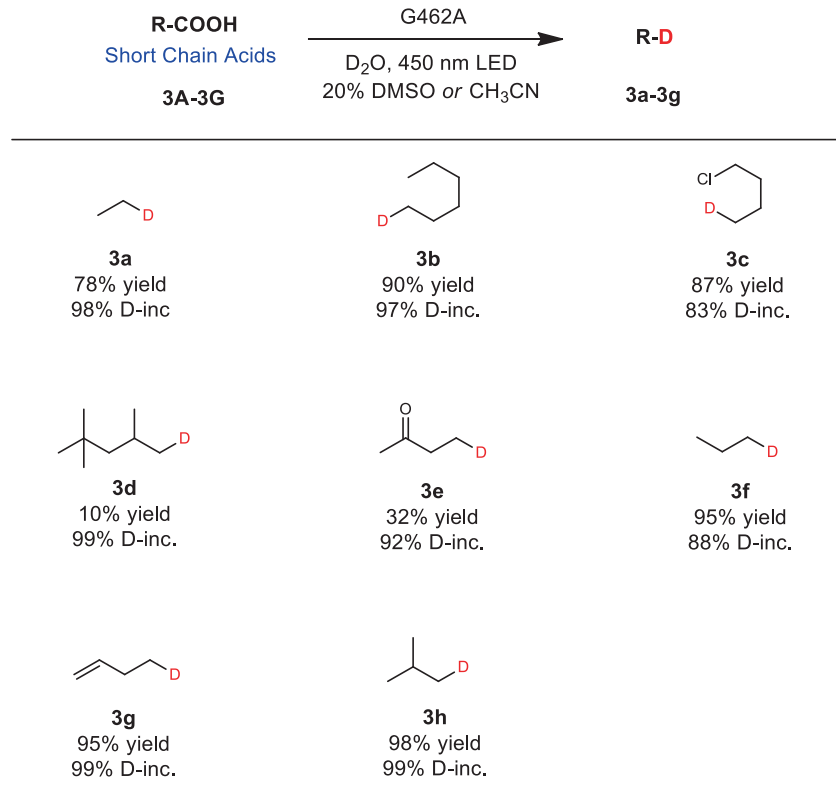

Fig. 4 Deuteration scope: short chain acids. Reaction conditions: Substrate (0.40 mmol), crude enzyme powder (containing CVFAP about $20 \mathrm{mg}$ ), $\mathrm{D}_{2} \mathrm{O}$ (4 mL), DMSO or $\mathrm{CH}_{3} \mathrm{CN}(1 \mathrm{~mL}), 450 \mathrm{~nm} L E D, 20^{\circ} \mathrm{C}, 12 \mathrm{~h}$. Yields were determined by GC. D-inc. data were determined by ${ }^{1} \mathrm{H}$ NMR or HRMS.

noteworthy is that the gaseous deuterated compounds could also be obtained successfully by this method (Fig. 4, 3a, 3f-3h).

Generally, enzymes offer attractive stereoselectivity under mild conditions, complementing or replacing manufacturing processes based on traditional man-made catalysts. However, the development of an enzyme for enantioselective synthesis of these deuterated compounds remains a challenge. Based on our previous studies in the $C v$ FAP-catalyzed kinetic resolution of $\alpha$ functionalized carboxylic acids ${ }^{54}$, we envisioned that the chiral deuterated products could also be achieved by engineered $C \nu \mathrm{FAP}$. Since optically active ethers and carboxylic acids are important chiral building blocks in pharmaceutical chemistry, we chose 2(heptan-3-yloxy) acetic acid (4A) as an ideal model substrate for screening (Fig. 1g). WT-C $\nu$ FAP was found to be selective for the (R)-configuration with an enantiomeric ratio (e.r.) of 95:5. However, the carbon chain is too short to be accepted by WT$C \nu$ FAP, leading to low activity (yield $19 \%$ ). The yield did not increase with prolongation of reaction time ${ }^{51}$. Upon screening the original $C v$ FAP library, mutant I398R was found to be effective. A $40 \%$ yield with satisfactory preference for the $(R)$-configuration $($ e.r. $=94: 6)($ Fig. 1 g). Next, we wanted to see how the best mutant performs in the decarboxylative deuteration of other differently substituted carboxylic acids (Fig. 5). To our delight, a range of tested deuterated chiral ether products were obtained with good yields and stereoselectivity $(\mathbf{4 a}-\mathbf{4 i})$. However, due to the large structural difference, the activity and stereoselectivity of deuterated alcohol products decreased significantly $(\mathbf{4 j}, \mathbf{4 k})$. Further studies on directed evolution of highly stereoselective $\mathrm{C} v \mathrm{FAP}$ for such compounds or other synthetically useful chiral substrates are ongoing in our laboratory.

Directed evolution of $C v$ FAP furnished a complementary set of enzymatic catalysts that allow for the enantiodivergent deuteration. Residue $462 \mathrm{G}$, which is located in the binding region as a type of CAST site ${ }^{29,57}$, was identified as the key position related to stereoselectivity in this kinetic resolution ${ }^{54}$. The single G462F mutation inverted the absolute configuration of model substrate (4A) in favor of (S)-selectivity (Fig. 1g). We note that this is the first example of enantiodivergent evolution using $C \nu$ FAP. 


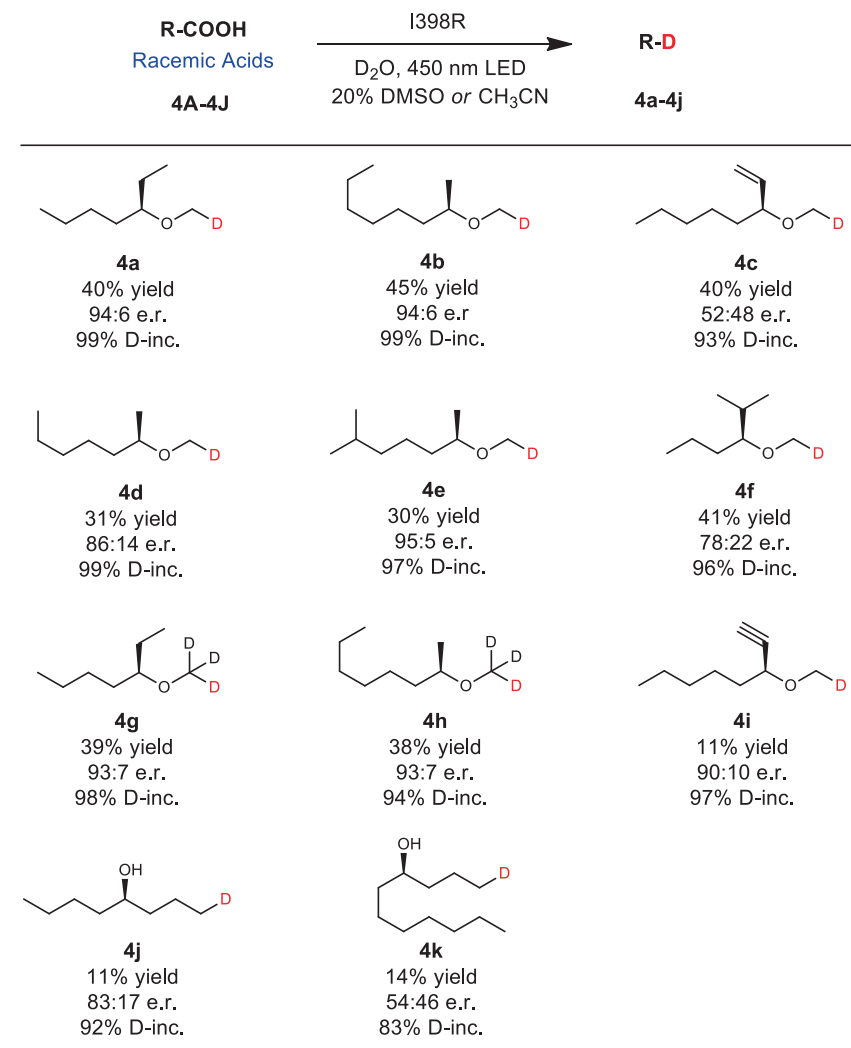

Fig. 5 Deuteration scope: racemic acids. Reaction conditions: Substrate ( $0.40 \mathrm{mmol}$ ), crude enzyme powder (containing CVFAP about $20 \mathrm{mg}$ ), $\mathrm{D}_{2} \mathrm{O}$ $(4 \mathrm{~mL}), \mathrm{DMSO}$ or $\mathrm{CH}_{3} \mathrm{CN}(1 \mathrm{~mL}), 450 \mathrm{~nm} \mathrm{LED}, 20^{\circ} \mathrm{C}, 12 \mathrm{~h}$. Yields and e.r. values were determined by chiral GC. D-inc. data were determined by ${ }^{1} \mathrm{H}$ NMR or HRMS. E.r. value of $\mathbf{4 e}$ was calculated based on the conversion and e.r. of $\mathbf{4 E}$.

Next, in order to improve activity in the reaction of bulky cyclic compounds, a final evolution route of CvFAP was explored. Residue Y466 was considered to play a dominant role in bulky substrate recognition, because it occupies a large space in the narrow tunnel near the active site, resulting in the stabilization of chain substrates by hydrophobic interactions ${ }^{49}$. Thus, Y466 was subjected individually to site-specific mutagenesis with the introduction of alanine (A) and glycine $(\mathrm{G})$ mutations to enlarge the binding tunnel, hopefully facilitating better substrate binding at the active site. Indeed, mutant Y466A induced activity significantly for 3-phenylbutanoic acid (5A) relative to WT-CvFAP (Figs. $1 \mathrm{~h}$ and 6). Remarkably, a series of bulky acids were also accepted well by the best mutant Y466A, good yields and D-incorporation being achieved (Fig. 6). This mutant also enabled the potential application of the biocatalytic decarboxylative reaction in the synthesis of complex deuterated compounds from biologically active natural products and drug molecules containing a carboxylic acid functional group, such as Gemfibrozil, Mycophenolic Acid, Zaltoprofen, and Dehydroabietic Acid in good D-incorporation $(\mathbf{5 h}-\mathbf{5 k})$. It can also be found that the yields of 5j-5k is not good probably due to the mutant Y466A can not accept the polycyclic structure well. In addition, the deuterated products achieved with such method could be further transformed into deuterated drug molecules. For example, 5d could be easily converted into chiral alcohol by ketoreductase ${ }^{61}$. Then, with the known synthetic route, the deuterium could be specifically introduced into (+)-Igmesine (Supplementary Fig. 8) ${ }^{62}$.

Scale-up experiment and $\mathrm{D}_{2} \mathrm{O}$ recycling. This light-driven decarboxylative deuteration method was easily scaled up. Treatment

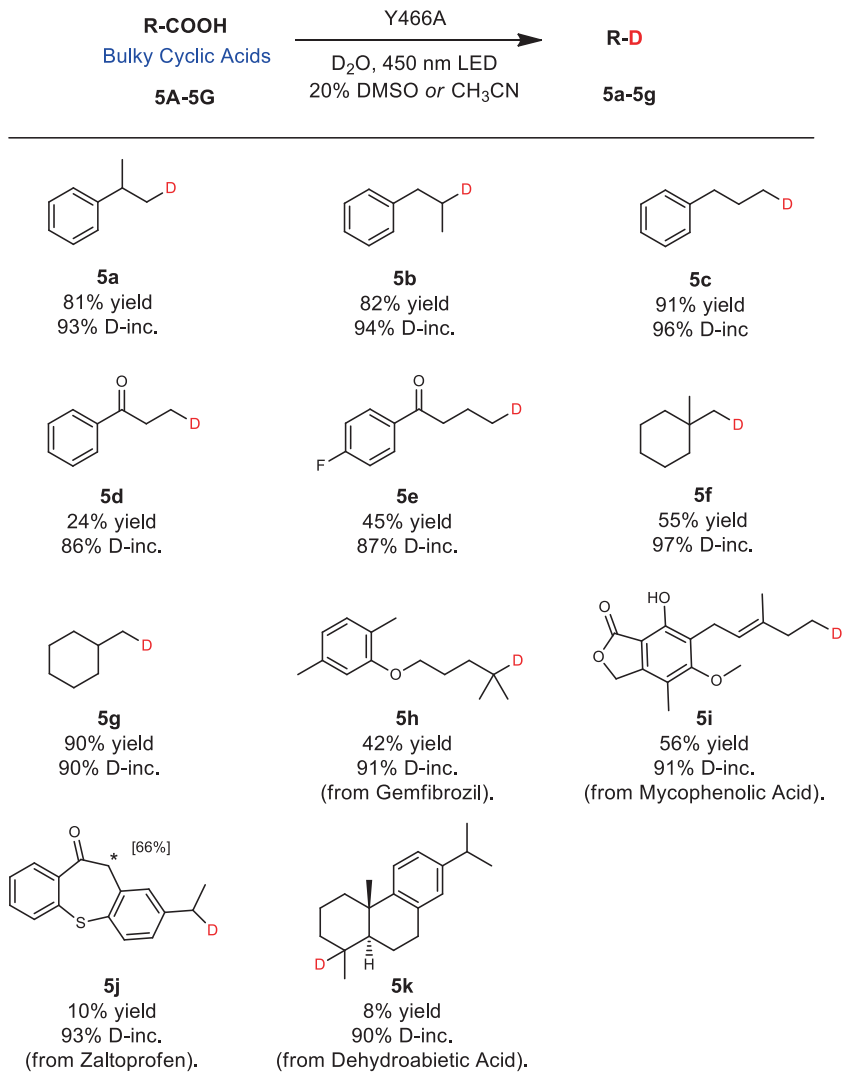

Fig. 6 Deuteration scope: bulky cyclic acids. Reaction conditions: Substrate $(0.40 \mathrm{mmol})$, crude enzyme powder (containing CvFAP about $20 \mathrm{mg}), \mathrm{D}_{2} \mathrm{O}(4 \mathrm{~mL}), \mathrm{DMSO}$ or $\mathrm{CH}_{3} \mathrm{CN}(1 \mathrm{~mL}), 450 \mathrm{~nm} \mathrm{LED}, 20^{\circ} \mathrm{C}, 12 \mathrm{~h}$. Yields were determined by GC. D-inc. data were determined by ${ }^{1} \mathrm{H}$ NMR or HRMS. *Non-enzymatic D-incorporation at C11 of $\mathbf{5} \mathbf{j}$ was also detected (see Supplementary Fig. 87).

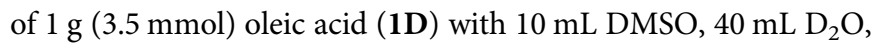
crude enzyme powder containing about $200 \mathrm{mg} C v \mathrm{FAP}$, followed by irradiation for $16 \mathrm{~h}$ at $20^{\circ} \mathrm{C}$. Simple extraction and purification steps were then implemented to afford desired product 1d with $68 \%$ yield $(567 \mathrm{mg})$ and $91 \% \mathrm{D}$-incorporation.

Furthermore, with a distillation of residual solvent, the recovered $\mathrm{D}_{2} \mathrm{O}$ could be used in next reaction without causing a decrease of the D-incorporation of C $v$ FAP (Supplementary Fig. 6).

Molecular dynamics (MD) simulations. In order to gain more insights into the differences in the catalytic activity and stereoselectivity of WT $C v$ FAP and the respective mutants in the presence of various substrates, we used MD simulations to model the enzymatic reactions. For medium chain acids and short chain acids, we found that the carboxyl of model substrates remains in close proximity to the N5 atom of FAD, favorable for SET to occur (Fig. 7a-d, Supplementary Figs. 9 and 10). For stereoselectivity, the distance between the carboxyl moiety of $(R)-2$ (heptan-3-yloxy) acetic acid (4A) to the N5 atom in FAD of $(R)$ selective I398R mutant is clearly shorter than that of the disfavored (S)-isomer (Fig. 7e, f, Supplementary Fig. 11). However, the opposite occurs in G462F (Fig. 7g, h, Supplementary Fig. 12), which is consistent with the reversed $(S)$-selectivity toward the 4 A substrate. Moreover, it was observed that the narrow binding tunnel of WT-C $v$ FAP (diameter: $7.1 \AA$ ) clearly hinders the access of the bulky substrate, such as 3-phenylbutanoic acid (5A) into the proximity of the active site (Fig. 7i). In mutant Y466A, the 

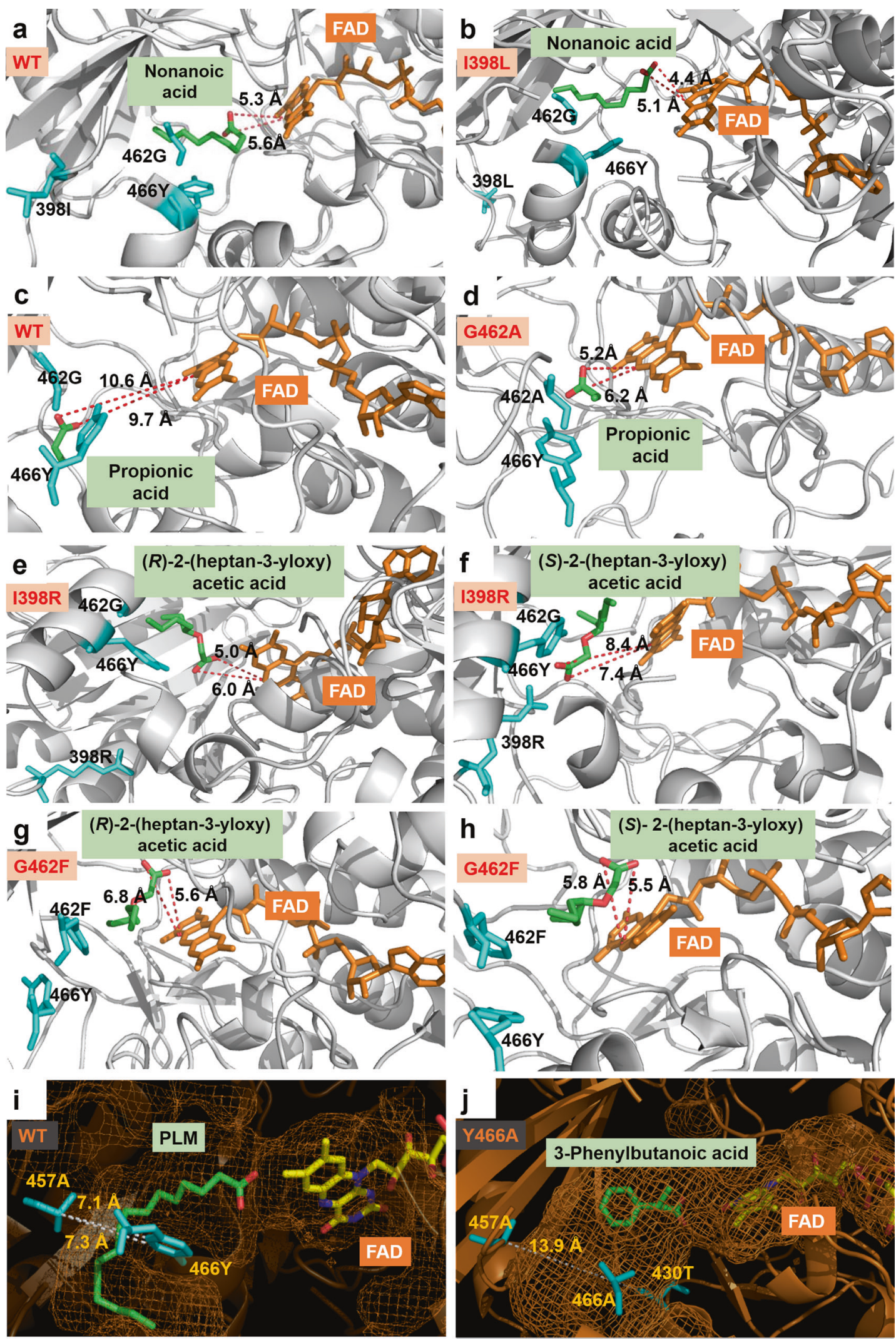

Fig. 7 MD simulations for gaining insight into the origins of the improved activity and stereoselectivity of CvFAPs. $\mathbf{a}$ and $\mathbf{b}$, for nonanoic acid. $\mathbf{c}$ and d, for butyric acid. e-h, for 2-(heptan-3-yloxy) acetic acid. $\mathbf{i}$ and $\mathbf{j}$, the change of the binding tunnel's diameter. The docked substrates (green), PLM (palmitic acid, green), FAD (yellow) and some important residues (cyan) are depicted as stick models. 
diameter of the binding tunnel is expanded to about $13.9 \AA$, which is large enough to accept the bulky acid (Fig. 7j, Supplementary Figs. 13 and 14).

In summary, we have demonstrated a photoinduced biocatalytic process for the deuteration of readily accessible carboxylic acids as starting materials and $\mathrm{D}_{2} \mathrm{O}$ as the deuterium source. In contrast to traditional photoinduced HAT processes, our method functions well under an air atmosphere without the requirement of thiol as additive. Although the substrate scope of typically biotransformation is narrow, divergent protein engineering was implemented through the FRISM strategy to permit the successful preparation of a diverse range of deuterated compounds in high yields and excellent $\mathrm{D}$-incorporation, and in relevant cases even with good enantioselectivity. Notably, the enantiodivergent directed evolution of $C v$ FAP was also achieved, allowing a series of chiral deuterated products to be obtained by engineered $\mathrm{C} v \mathrm{FAP}$ with good yields and stereoselectivity. Finally, the scale-up and $\mathrm{D}_{2} \mathrm{O}$ recycling experiments were implemented, which demonstrated the practical utility of this biocatalytic process. We anticipate that this ecologically and economically viable synthetic process for the preparation of deuterated compounds will be adopted in both academic and industrial fields.

\section{Methods}

General information. All chemical reagents were obtained from commercial sources unless otherwise noted. The ${ }^{1} \mathrm{H}$ and ${ }^{13} \mathrm{C}$ NMR spectra were recorded with a Bruker AMX400 MHz spectrometer using TMS as an internal standard. All compounds were characterized by high resolution mass spectra (HRMS) (Waters GCT PremierTM orthogonal acceleration time-of-flight (oa-TOF) mass spectrometry with an EI Source). GC yields and e.r. values were recorded by SHIMADZU ${ }^{\text {tix }}$ GCsolution software version 3 in GC-2014 gas chromatography system with Agilent CP-chirasil-Dex CB (FID, $\mathrm{N}_{2}$ as the carrier gas).

PCR based methods for the construction of CvFAP library. PCR reactions were performed using WT-FAP plasmid (pET28b) as the DNA template, and forward primers (see Supplementary Table 1) and a silent reverse primer (GATGCCGGGAGCAGACAAGCCCGTCAGGGCGC). The reaction (50 $\mu \mathrm{L}$ final volume) contained: $\mathrm{ddH}_{2} \mathrm{O}(31 \mu \mathrm{L})$, KOD 10X buffer $(5 \mu \mathrm{L})$, dNTP $(5 \mu \mathrm{L}, 2 \mathrm{mM}$ each), forward primers $(1.5 \mu \mathrm{L}, 10 \mu \mathrm{M}$ each), silent reverse primer $(1.5 \mu \mathrm{L}, 10 \mu \mathrm{M}$ each), template plasmid $(1.0 \mu \mathrm{L}, 100 \mathrm{ng} / \mu \mathrm{L}$ each), $1 \mu \mathrm{L}$ of DMSO and $1 \mu \mathrm{L}$ of KOD-plus-Neo. PCR conditions used were $94^{\circ} \mathrm{C}, 2 \mathrm{~min} ; 30 \mathrm{cycles}$ of $\left(98^{\circ} \mathrm{C}, 10 \mathrm{sec} ; 55^{\circ} \mathrm{C}, 30 \mathrm{sec} ; 68^{\circ} \mathrm{C}, 5\right.$ min) and final extension at $68^{\circ} \mathrm{C}, 10 \mathrm{~min}$. To ensure the elimination of the circular polymethylated template plasmid, $50 \mu \mathrm{L}$ of PCR reaction mixture was mixed with $2 \mu \mathrm{L}$ Dpn I $(10 \mathrm{U} / \mu \mathrm{L})$ and incubated overnight at $37^{\circ} \mathrm{C}$, followed by an additional $2 \mu \mathrm{L}$ of Dpn I for $3.0 \mathrm{~h}$. Upon purification of the Dpn I-digested product with an Omega PCR purification spin column, an aliquot of $20 \mu \mathrm{L}$ was used to transform $80 \mu \mathrm{L}$ of $E$. coli BL21 electrocompetent cells. The transformation mixture was incubated with $1 \mathrm{~mL}$ of LB medium at $37^{\circ} \mathrm{C}$ with shaking, and then spread on LBagar plates containing Kanamycin $(50 \mu \mathrm{g} / \mathrm{mL})$. A single colony from a plate was incubated in $5 \mathrm{~mL}$ of $\mathrm{LB}$ medium at $37^{\circ} \mathrm{C}$ overnight, and the plasmid was then extracted with an Omega gel extraction column. DNA was sequenced by Sangon Biotech (Shanghai, China). Target mutant was stored with glycerol at $-80{ }^{\circ} \mathrm{C}$.

Protein expression. $100 \mu \mathrm{L}$ of stored bacteria was first inoculated in $5 \mathrm{~mL}$ of LB medium (containing $50 \mu \mathrm{g} / \mathrm{mL}$ Kanamycin), and was shaken at $200 \mathrm{rpm}$ overnight as preculture. The preculture was used to inoculate large culture $(250 \mathrm{~mL} \mathrm{~TB}+50$ $\mu \mathrm{g} / \mathrm{mL}$ kanamycin in $1 \mathrm{~L}$ shake flasks) at $37^{\circ} \mathrm{C}$ for about $4 \mathrm{~h}$ until $\mathrm{OD}_{600}$ at $0.6-0.8$. After cooling at $4^{\circ} \mathrm{C}$ for $1 \mathrm{~h}, 0.2 \mathrm{mM}$ isopropyl $\beta$-thiogalactopyranoside (IPTG) was added to induce $C \nu$ FAP expression. The culture was allowed to express at $20^{\circ} \mathrm{C}$ for $24 \mathrm{~h}$ with shaking at $200 \mathrm{rpm}$. Then, cells were harvested by centrifugation at $4500 \times g$ and $4{ }^{\circ} \mathrm{C}$ for $25 \mathrm{~min}$ and the supernatants were discarded. The cells were resuspended in the same buffer $(1 \mathrm{~g}$ wet cell in $10 \mathrm{~mL}$ of phosphate buffer, $50 \mathrm{mM}$, $\mathrm{pH}$ 8.5) and stored at $-80^{\circ} \mathrm{C}$. The cells were repeated freezing and thawing for 3 times, and then released the target proteins by sonication. The cell debris were removed by centrifugation at $20,130 \times g$ for $15 \mathrm{~min}$ at $4^{\circ} \mathrm{C}$, the enzyme solutions were stored at $-80^{\circ} \mathrm{C}$ for further reaction.

Preparation of crude enzyme powder. The frozen crude enzyme solutions were dried in low temperature vacuum for about $10 \mathrm{~h}$. Take care to avoid excessive freeze-drying which probably results in the loss of bound water.

Protein purification. The crude enzyme solution was filtered and loaded on a GE Healthcare HisTrap FF Crude column $(5 \mathrm{~mL})$ preequilibrated with $50 \mathrm{mM}$ of phosphate buffer ( $\mathrm{pH} 7.4$ ) containing $0.5 \mathrm{M} \mathrm{NaCl}$ and $5 \mathrm{mM}$ imidazole. The enzyme was eluted by $50 \mathrm{mM}$ phosphate buffer with $0.5 \mathrm{M} \mathrm{NaCl}$ and $200 \mathrm{mM}$ imidazole. The proteins were dialyzed by $50 \mathrm{mM}$ of phosphate buffer ( $\mathrm{pH} \mathrm{8.5)}$ for $12 \mathrm{~h}$ at $4^{\circ} \mathrm{C}$.

General procedure for screening. $0.02 \mathrm{Mmol}$ of substrate was dissolved in $200 \mu \mathrm{L}$ DMSO, and then was added to $1 \mathrm{~mL}$ of crude enzyme solutions of different mutants ( $1 \mathrm{~g}$ wet cell in $10 \mathrm{~mL}$ pH 8.5 phosphate buffer). The mixture was shaken at $1500 \mathrm{rpm}$ under the irradiation of Blue LEDs for $12 \mathrm{~h}$ at $20^{\circ} \mathrm{C}$, then extracted with ethyl acetate for three times. The yields and e.r. values were determined by gas chromatography.

Determination of turnover frequency (TOF). The TOF determination for WT$C v$ FAP and mutants were performed in phosphate buffer $\left(\mathrm{H}_{2} \mathrm{O}\right.$ or $\mathrm{D}_{2} \mathrm{O}, \mathrm{pH}$ or $\mathrm{pD}=8.5)$ at $1500 \mathrm{rpm}$ and $20^{\circ} \mathrm{C}$ under the irradiation of Blue LED in presence of 5-10 mM (excess substrate) substrate and $10 \mu \mathrm{M}$ FAD-loading enzyme for $1 \mathrm{~h}$ (FAD-loading was determined by the absorbance at $460 \mathrm{~nm}$ ). The TOF was calculated with the formula: (Conc.(product) $/$ Conc.(FAD-bound $\mathrm{C} v \mathrm{FAP}_{\text {) }}$ )/reaction time.

General procedure for decarboxylative deuteration. $4 \mathrm{~mL}$ of $\mathrm{D}_{2} \mathrm{O}(8 \mathrm{~mL}$ for medium chain acids) containing substrate $(0.40 \mathrm{mmol}$, dissolved in $1 \mathrm{~mL}$ DMSO or $\mathrm{CH}_{3} \mathrm{CN}$ ) and crude enzyme powder (containing $\mathrm{C} v \mathrm{FAP}$ about $20 \mathrm{mg}$ ) was irradiated by $450 \mathrm{~nm}$ LED at $20^{\circ} \mathrm{C}$ for $12 \mathrm{~h}$. The mixture was then extracted with ethyl acetate for three times. Yields and e.r. values (absolute configurations confirmed by the corresponding $R$-ethers which were synthesized from $R$-alcohols) were determined by GC. Then, the mixture was extracted with DCM and evaporated under reduced pressure, and purified by column chromatography (petroleum ether/ethyl acetate). The D-incorporation was determined by NMR (for products with high boiling points) or HRMS (for products with low boiling points or gaseous products). Note: the D-incorporations of deuterated hydrocarbons with low boiling points were further corrected by comparing their MS data with that of corresponding hydrocarbons without deuterium, due to the EI-MS could generate M-1 peaks for the detection of hydrocarbons with low boiling points (especially gaseous hydrocarbons). With the boiling point of the alkane increases (higher than hexane), the signal of M-1 peaks will disappear (Supplementary Table 2). Moreover, Dincorporations of some volatile deuterated hydrocarbons were also determined by HRMS because low-temperature distillation which was necessary for the concentration of volatile deuterated products during the purification, sometimes could not remove the residual eluent completely and some NMR signals of the residual elution solvents in the range of $0-1 \mathrm{ppm}$ disturbed the accurate determination of D-incorporations by NMR. Alcohols and ketones were performed H-D exchange with $1 \mathrm{M} \mathrm{NaOH}$ solution before determined. All D-incorporation determined data were shown in Supplementary Tables (pages 39-103).

Scaling-up decarboxylative deuteration. The scale-up reaction was performed as follows: a flask containing $40 \mathrm{~mL}$ of $\mathrm{D}_{2} \mathrm{O}$ with crude enzyme powder (containing about $200 \mathrm{mg} C \nu \mathrm{FAP})$ and $1 \mathrm{~g}(3.5 \mathrm{mmol})$ oleic acid was shaken at $200 \mathrm{rpm}$ and $20^{\circ} \mathrm{C}$ for about $16 \mathrm{~h}$. The mixture was extracted with ethyl acetate for three times. The organic phase was evaporated under reduced pressure, and purified by column chromatography to provide $\mathbf{1 d}$ with $68 \%$ yield $(567 \mathrm{mg}$ ) and $91 \% \mathrm{D}$-incorporation.

General synthesis procedure of $\alpha$-alkoxy carboxylic acids. To a solution of sodium hydride $(1.20 \mathrm{~g}, 30 \mathrm{mmol})$ in dry THF $(20 \mathrm{~mL})$ at $0{ }^{\circ} \mathrm{C}$ under $\mathrm{N}_{2}$ atmosphere, dry THF $(30 \mathrm{~mL})$ containing various alcohols $(10 \mathrm{mmol})$ was added slowly for about $30 \mathrm{~min}$. Then dry THF $(30 \mathrm{~mL})$ containing bromoacetic acid $(10 \mathrm{mmol})$ was added dropwise. The reaction was performed under the reflux conditions and was monitored by TLC. After completion, $60 \mathrm{~mL}$ water was added into the cooled reaction mixture, and $2 \mathrm{M} \mathrm{HCl}$ was used to acidize the aqueous layer to $\mathrm{pH} 2$. Hexane and diethyl ether were used to extract the organic layer for three times, respectively. Various pure $\alpha$-alkoxy carboxylic acids can be obtained after column chromatography on silica gel with the eluent of petroleum ether/ethyl acetate.

Molecular docking. Molecular docking calculations were performed by the AutoDock4.2.6 software ${ }^{63}$. After deleting the environmental waters and the sodium counterions, the MD-equilibrated structures of the WT-CvFAP and mutants were set as receptors. Nonanoic acid, butyric acid, 2-(heptan-3-yloxy) acetic acid and benzyl butyrate were set as the substrates with all their rotatable bonds set flexible, respectively. To include all possible binding conformations, a large cubic box comprised of $60 \times 60 \times 60$ girds with the grid spacing of $0.375 \AA$ was used for the docking calculations. Lamarckian genetic algorithm was applied, and each docking calculation contained 150 genetic algorithm runs. The default values were used for all the other parameters. The first conformations of the largest groups in the docking results were selected as the bioactive bindings.

Molecular dynamics. MD simulations were performed using the AMBER 12 software $^{64}$. The FF14SB force field was applied for the $C v$ FAP protein ${ }^{65}$, the reported parameter for the FAD was used ${ }^{66}$, and the restricted electrostatic potential (RESP) atomic charges and the force field parameters generated using the 
Antechamber module of AmberTools were applied for different target compounds ${ }^{67}$. The $C v$ FAP proteins and the binding complexes were individually immersed into the center of a truncated octahedron box of TIP3P water molecules with a margin distance of $12.0 \AA, \mathrm{Na}^{+}$counterions were added by using the AMBER TLEAP module to keep system in electric neutrality ${ }^{64}$. Each system was firstly energy minimized by the steepest descent method for 5000 steps with the protein or binding complex restricted by a harmonic constraint of $100 \mathrm{kcal} \cdot \mathrm{mol}^{-1} \AA^{-2}$. A further conjugate gradient minimization of 5000 steps was performed with no constraint. Then the system was gradually heated from $0 \mathrm{~K}$ to $300 \mathrm{~K}$ under the NVT ensemble over a period of $500 \mathrm{ps}$, during which the Langevin thermostat with a coupling coefficient of $1.0 \mathrm{ps}$ and a weak constraint of $10 \mathrm{kcal} \cdot \mathrm{mol}^{-1} \AA^{-2}$ on the protein or binding complex was applied. Each calculation model was then subjected to an equilibrium simulation for $1 \mathrm{~ns}$ in order to remove all constraints. The production MD simulations were conducted under NPT ensemble at $300 \mathrm{~K}$ for 100 or 150 ns. Periodic boundary conditions were used with a cutoff radius of $12 \AA$ and long-range electrostatic interactions were performed using Particle Mesh Ewald (PME) method ${ }^{68}$. The Berendsen barostat was used to maintain the pressure at 1 bar. The SHAKE algorithm was used to constrain all the covalent bonds involving hydrogen atoms ${ }^{69}$. The time step was set to $2 \mathrm{fs}$ and the individual frames were saved every 10 ps during the production run. All structural figures were prepared using Pymol (http://www.pymol.org//70. All supplementary figures for the comparison of the distance between the carboxyl of substrates and the N5 atom of FAD in variants by MD simulation were prepared using OriginPro (https://www. originlab.com/).

Reporting summary. Further information on research design is available in the Nature Research Reporting Summary linked to this article.

\section{Data availability}

The data supporting the findings of this study are available within the paper and it supplementary information files. The source data underlying Figs. $1 \mathrm{~d}-\mathrm{f}$ and $\mathrm{h}$, and Supplementary Figs. 1-7 and Supplementary Table 3 are provided as a source data file. PDB file used in this study is available in Protein Data Bank (PDB) (ID: 5NCC, https:// www1.rcsb.org/structure/5NCC). Source data are provided with this paper.

Received: 13 October 2020; Accepted: 10 June 2021;

Published online: 25 June 2021

\section{References}

1. Isin, E. M., Elmore, C. S., Nilsson, G. N., Thompson, R. A. \& Weidolf, L. Use of radiolabeled compounds in drug metabolism and pharmacokinetic studies. Chem. Res. Toxicol. 25, 532-542 (2012).

2. Elmore, C. S. \& Bragg, R. A. Isotope chemistry; a useful tool in the drug discovery arsenal. Bioorg. Med. Chem. Lett. 25, 167-171 (2015)

3. Elmore, C. S. The use of isotopically labeled compounds in drug discovery. Annu. Rep. Med. Chem. 44, 515-534 (2009).

4. Gant, T. G. Using deuterium in drug discovery: leaving the label in the drug. J. Med. Chem. 57, 3595-3611 (2014).

5. Schmidt, C. First deuterated drug approved. Nat. Biotechnol. 35, 493-494 (2017).

6. Soulard, V., Villa, G., Vollmar, D. P. \& Renaud, P. Radical deuteration with D2O: catalysis and mechanistic insights. J. Am. Chem. Soc. 140, 155-158 (2018).

7. Yu, R. P., Hesk, D., Rivera, N., Pelczer, I. \& Chirik, P. J. Iron-catalysed tritiation of pharmaceuticals. Nature 529, 195-199 (2016).

8. Kerr, W. J., Reid, M. \& Tuttle, T. Iridium-catalyzed formyl-selective deuteration of aldehydes. Angew. Chem. Int. Ed. 56, 7808-7812 (2017).

9. Valero, M., Weck, R., Guessregen, S., Atzrodt, J. \& Derdau, V. Highly selective directed iridium-catalyzed hydrogen isotope exchange reactions of aliphatic amides. Angew. Chem. Int. Ed. 57, 8159-8163 (2018).

10. Chang, Y. et al. Catalytic deuterium incorporation within metabolically stable beta-amino C-H bonds of drug molecules. J. Am. Chem. Soc. 141, 14570-14575 (2019).

11. Atzrodt, J., Derdau, V., Kerr, W. J. \& Reid, M. C-H functionalisation for hydrogen isotope exchange. Angew. Chem. Int. Ed. 57, 3022-3047 (2018).

12. Twilton, J. et al. The merger of transition metal and photocatalysis. Nat. Rev. Chem. 1, 19 (2017).

13. Loh, Y. Y. et al. Photoredox-catalyzed deuteration and tritiation of pharmaceutical compounds. Science 358, 1182-1187 (2017).

14. Barker, G. et al. Gold-catalyzed proto- and deuterodeboronation. J. Org. Chem. 80, 9807-9816 (2015)

15. Alonso, F., Beletskaya, I. P. \& Yus, M. Metal-mediated reductive hydrodehalogenation of organic halides. Chem. Rev. 102, 4009-4091 (2002).
16. Rudzki, M., Alcalde-Aragonés, A., Dzik, W. I., Rodríguez, N. \& Gooßen, L. J Selective copper- or silver-catalyzed decarboxylative deuteration of aromatic carboxylic acids. Synthesis 44, 184-193 (2012).

17. Grainger, R., Nikmal, A., Cornella, J. \& Larrosa, I. Selective deuteration of (hetero)aromatic compounds via deutero-decarboxylation of carboxylic acids. Org. Biomol. Chem. 10, 3172-3174 (2012).

18. Zhan, K. \& Li, Y. Microwave-assisted silver-catalyzed protodecarboxylation and decarboxylative iodination of aromatic carboxylic acids. Catalysts 7, 314 (2017).

19. Tsukuda, K. \& Onomura, O. Nickel-catalyzed deoxygenative deuteration of aryl sulfamates. Adv. Synth. Catal. 359, 1043-1048 (2017).

20. Janni, M. \& Peruncheralathan, S. Catalytic selective deuteration of halo (hetero) arenes. Org. Biomol. Chem. 14, 3091-3097 (2016).

21. Constantin, T. et al. Aminoalkyl radicals as halogen-atom transfer agents for activation of alkyl and aryl halides. Science 367, 1021-1026 (2020).

22. Liu, C. et al. Controllable deuteration of halogenated compounds by photocatalytic D2O splitting. Nat. Commun. 9, 80 (2018).

23. Bhadra, S., Dzik, W. I. \& Goossen, L. J. Decarboxylative etherification of aromatic carboxylic acids. J. Am. Chem. Soc. 134, 9938-9941 (2012).

24. Weaver, J. D., Recio, A. III, Grenning, A. J. \& Tunge, J. A. Transition metal catalyzed decarboxylative allylation and benzylation reactions. Chem. Rev. 111, 1846-1913 (2011).

25. Patra, T., Mukherjee, S., Ma, J., Strieth-Kalthoff, F. \& Glorius, F. Visible-lightphotosensitized aryl and alkyl dcarboxylative functionalization reactions. Angew. Chem. Int. Ed. 58, 10514-10520 (2019).

26. Itou, T. et al. A mild deuterium exchange reaction of free carboxylic acids by photochemical decarboxylation. Chem. Commun. 46, 6177-6179 (2010).

27. Arnold, F. H. Innovation by evolution: bringing new chemistry to life (Nobel Lecture). Angew. Chem. Int. Ed. 58, 14420-14426 (2019).

28. Devine, P. N. et al. Extending the application of biocatalysis to meet the challenges of drug development. Nat. Rev. Chem. 2, 409-421 (2018).

29. Qu, G., Li, A. T., Acevedo-Rocha, C. G., Sun, Z. T. \& Reetz, M. T. The crucial role of methodology development in directed evolution of selective enzymes. Angew. Chem. Int. Ed. 59, 13204-13231 (2020).

30. Bornscheuer, U. T. et al. Engineering the third wave of biocatalysis. Nature 485, 185-194 (2012).

31. Rowbotham, J. S., Ramirez, M. A., Lenz, O., Reeve, H. A. \& Vincent, K. A. Bringing biocatalytic deuteration into the toolbox of asymmetric isotopic labelling techniques. Nat. Commun. 11, 1454 (2020).

32. Chun, S. W. \& Narayan, A. R. H. Biocatalytic, stereoselective deuteration of $\alpha$ amino acids and methyl esters. ACS Catal. 10, 7413-7418 (2020).

33. Wong, C. H. \& Whitesides, G. M. Enzyme-catalyzed organic synthesis: regeneration of deuterated nicotinamide cofactors for use in large-scale enzymatic synthesis of deuterated substances. J. Am. Chem. Soc. 105, 5012-5014 (1983).

34. Edegger, K. et al. Biocatalytic deuterium- and hydrogen-transfer using overexpressed ADH-'A': enhanced stereoselectivity and $2 \mathrm{H}$-labeled chiral alcohols. Chem. Commun. 5, 2402-2404 (2006).

35. Zhang, Z., Chen, L., Liu, L., Su, X. \& Rabinowitz, J. D. Chemical basis for deuterium labeling of fat and NADPH. J. Am. Chem. Soc. 139, 14368-14371 (2017).

36. Thompson, L. A. et al. Rapid, heterogeneous biocatalytic hydrogenation and deuteration in a continuous flow reactor. ChemCatChem 12, 3913-3918 (2020)

37. Al-Shameri, A. et al. Powering artificial enzymatic cascades with electrical energy. Angew. Chem. Int. Ed. 59, 10929-10933 (2020).

38. Rowbotham, J. S., Reeve, H. A. \& Vincent, K. A. Hybrid chemo-, bio-, and electrocatalysis for atom-efficient deuteration of cofactors in heavy water. ACS Catal. 11, 2596-2604 (2021)

39. Pajak, M., Pałka, K., Winnicka, E. \& Kańska, M. The chemo- enzymatic synthesis of labeled L-amino acids and some of their derivatives. J. Radioanal. Nucl. Chem. 317, 643-666 (2018).

40. Pajak, M. \& Kańska, M. Enzymatic syntheses of $3^{\prime}$-halotyramines, selectively $2 \mathrm{H}-$ and $3 \mathrm{H}$-labeled in the side chain. Appl. Radiat. Isot. 131, 8-12 (2018).

41. Dragulska, S. \& Kańska, M. Enzymatic synthesis of tryptamine and its halogen derivatives selectively labeled with hydrogen isotopes. J. Radioanal. Nucl. Chem. 299, 759-763 (2014).

42. Huang, X. et al. Photoenzymatic enantioselective intermolecular radical hydroalkylation. Nature 584, 69-74 (2020).

43. Nakano, Y. et al. Photoenzymatic hydrogenation of heteroaromatic olefins using 'Ene'-reductases with photoredox catalysts. Angew. Chem. Int. Ed. 59, 10484-10488 (2020).

44. Black, M. J. et al. Asymmetric redox-neutral radical cyclization catalysed by flavin-dependent 'ene'-reductases. Nat. Chem. 12, 71-75 (2020).

45. Sandoval, B. A., Kurtoic, S. I., Chung, M. M., Biegasiewicz, K. F. \& Hyster, T. K. Photoenzymatic catalysis enables radical-mediated ketone reduction in enereductases. Angew. Chem. Int. Ed. 58, 8714-8718 (2019).

46. Biegasiewicz, K. F. et al. Photoexcitation of flavoenzymes enables a stereoselective radical cyclization. Science 364, 1166-1169 (2019). 
47. Biegasiewicz, K. F., Cooper, S. J., Emmanuel, M. A., Miller, D. C. \& Hyster, T. K. Catalytic promiscuity enabled by photoredox catalysis in nicotinamidedependent oxidoreductases. Nat. Chem. 10, 770-775 (2018).

48. Emmanuel, M. A., Greenberg, N. R., Oblinsky, D. G. \& Hyster, T. K. Accessing non-natural reactivity by irradiating nicotinamide-dependent enzymes with light. Nature 540, 414-417 (2016).

49. Sorigué, D. et al. An algal photoenzyme converts fatty acids to hydrocarbons. Science 357, 903-907 (2017).

50. Huijbers, M. M. E., Zhang, W. Y., Tonin, F. \& Hollmann, F. Light-driven enzymatic decarboxylation of fatty acids. Angew. Chem. Int. Ed. 57, 13648-13651 (2018).

51. Zhang, W. Y. et al. Hydrocarbon synthesis via photoenzymatic decarboxylation of carboxylic acids. J. Am. Chem. Soc. 141, 3116-3120 (2019).

52. Cha, H.-J. et al. Whole-cell photoenzymatic cascades to synthesize long-chain aliphatic amines and esters from renewable fatty acids. Angew. Chem. Int. Ed. 59, 2024-7028 (2020).

53. Amer, M. et al. Low carbon strategies for sustainable bio-alkane gas production and renewable energy. Energy Environ. Sci. 13, 1818 (2020).

54. Xu, J. et al. Light-driven kinetic resolution of alpha-functionalized carboxylic acids enabled by an engineered fatty acid photodecarboxylase. Angew. Chem. Int. Ed. 58, 8474-8478 (2019).

55. Sorigué, D. et al. Mechanism and dynamics of fatty acid photodecarboxylase. Science 372, 148 (2021).

56. Heyes, D. J. et al. Photochemical mechanism of light-driven fatty acid photodecarboxylase. ACS Catal. 10, 6691-6696 (2020).

57. Acevedo-Rocha, C. G., Kille, S. \& Reetz, M. T. Iterative saturation mutagenesis: A powerful approach to engineer proteins by simulating Darwinian evolution. Methods Molec. Biol. 1179, 103-128 (2014).

58. $\mathrm{Xu}$, J. et al. Stereodivergent protein engineering of a lipase to access all possible stereoisomers of chiral esters with two stereocenters. J. Am. Chem. Soc. 141, 7934-7945 (2019).

59. Li, D., Wu, Q. \& Reetz, M. T. Focused rational iterative site-specific mutagenesis (FRISM). Methods Enzymol. 643, 225-242 (2020).

60. Li, J. et al. Nearperfect control of the regioselective glucosylation enabled by rational design of glycosyltransferases. Green. Synth. Catal. 2, 45-53 (2021).

61. Xu, J. et al. Enantiocomplementary decarboxylative hydroxylation combining photocatalysis and whole-cell biocatalysis in a one-pot cascade process. Green. Chem. 21, 1907-1911 (2019).

62. Bagutski, V., Elford, T. G. \& Aggarwal, V. K. Synthesis of highly enantioenriched C-tertiary amines from boronic esters: application to the synthesis of Igmesine. Angew. Chem. Int. Ed. 50, 1080-1083 (2011).

63. Morris, G. M. et al. AutoDock4 and AutoDockTools4: Automated Docking with selective receptor flexibility. J. Comput. Chem. 30, 2785-2791 (2009).

64. Case, D. A. et al. The Amber biomolecular simulation programs. J. Comput. Chem. 26, 1668-1688 (2005).

65. Maier, J. A. et al. ff14SB: Improving the accuracy of protein side chain and backbone parameters from ff99SB. J. Chem. Theory Comput. 11, 3696-3713 (2015).

66. Antony, J., Medvedev, D. M. \& Stuchebrukhov, A. A. Theoretical study of electron transfer between the photolyase catalytic cofactor FADH- and DNA thymine dimer. J. Am. Chem. Soc. 122, 1057-1065 (2000).

67. Wang, Z. et al. Combined 3D-QSAR, molecular docking and molecular dynamics study on the benzimidazole inhibitors targeting HCV NS5B polymerase. J. Biomol. Struct. Dyn. 38, 1071-1082 (2020).

68. Essmann, U. et al. A smooth particle mesh Ewald method. J. Chem. Phys. 103, 8577-8593 (1995).
69. Ryckaert, J. P., Ciccotti, G. \& Berendsen, H. J. C. Numerical integration of the cartesian equations of motion of a system with constraints: molecular dynamics of n-alkanes. J. Comput. Phys. 23, 327-341 (1977).

70. DeLano, W. L. The PyMOL Molecular Graphics System. (DeLano Scientific, San Carlos, CA, USA, 2002).

\section{Acknowledgements}

This research was funded by National Natural Science Foundation of China (Nos. 91956128, 22111530114), Zhejiang Provincial Natural Science Foundation (No LY19B020014) and National Key Research and Development Program of China (to Q.W. and J.X.), and by Scientific Research Starting Foundation of Zhejiang University of Technology (No. 2020105009029) (to J.X.). We thank Dr. Jiankai Zou at Analysis and Test Platform of Department of Chemistry, Zhejiang University for assistance during HRMS determination.

\section{Author contributions}

J.X., J.F., Y.L., W.X. and Z.W. contributed equally to this work. J.X. and Q.W. conceived and designed the study. J.X., J.F., Y.L., W.X., D.L. and H.Z. performed the experiments. Z. W. performed the MD simulation. Q.W., J.X. and X.L. analyzed the data. Q.W. and J.X. wrote the manuscript. All authors checked the manuscript.

\section{Competing interests}

The authors declare no competing interests.

\section{Additional information}

Supplementary information The online version contains supplementary material available at https://doi.org/10.1038/s41467-021-24259-6.

Correspondence and requests for materials should be addressed to J.X. or Q.W.

Peer review information Nature Communications thanks Frank Hollmann and the other anonymous reviewer(s) for their contribution to the peer review of this work. Peer reviewer reports are available.

Reprints and permission information is available at http://www.nature.com/reprints

Publisher's note Springer Nature remains neutral with regard to jurisdictional claims in published maps and institutional affiliations.

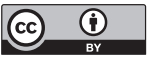

Open Access This article is licensed under a Creative Commons Attribution 4.0 International License, which permits use, sharing, adaptation, distribution and reproduction in any medium or format, as long as you give appropriate credit to the original author(s) and the source, provide a link to the Creative Commons license, and indicate if changes were made. The images or other third party material in this article are included in the article's Creative Commons license, unless indicated otherwise in a credit line to the material. If material is not included in the article's Creative Commons license and your intended use is not permitted by statutory regulation or exceeds the permitted use, you will need to obtain permission directly from the copyright holder. To view a copy of this license, visit http://creativecommons.org/ licenses/by/4.0/

(C) The Author(s) 2021 